\title{
APPROACHES FOR GASTRORETENTIVE DRUG DELIVERY SYSTEMS-A REVIEW
}

\author{
Parveen Kumar*, Nirmala, SL Hari Kumar \\ Rayat \& Bahra Institute of Pharmacy, Sahauran, Mohali, Punjab, India \\ *Corresponding Author's E-mail: parveenchaudhary3@gmail.com
}

\begin{abstract}
The purpose of writing this review on gastro retentive drug delivery systems was to compile the recent literature with special focus on floating drug delivery systems (FDDS) to achieve gastric retention. FDDS are of particular interest for drugs that are locally active and have narrow absorption window in stomach or upper small intestine, unstable in the intestinal or colonic environment, and exhibit low solubility at high $\mathrm{pH}$ value. It is known that differences in gastric physiology (such as, gastric $\mathrm{pH}$, motility) exhibit both intra as well as inter subject variability demonstrating significant impact on gastric retention time and drug delivery behaviour.Thus, gastroretention helps to increase the gastric residence time and improve absorption of drugs with narrow absorption window. The recent developments of FDDS including the pharmacokinetic and pharmacodynamic aspects affecting gastric retention, approaches to design single-unit and multiple- unit floating systems, advantages and limitations over the conventional drug delivery systems, and their classification and formulation aspects are covered in detail. This review also summarizes the studies to evaluate the performance and application of floating systems, and applications of these systems.

Key Words: Floating matrix, gastrointestinal, gastro retentive, system, evaluation.
\end{abstract}

\section{INTRODUCTION}

The gastric emptying of dosage forms is an extremely variable process and ability to prolong and control the emptying time is a valuable asset for dosage forms that reside in the stomach for a longer period of time than conventional dosage forms. There are many difficulties faced in designing controlled release systems for better absorption and enhanced bioavailability. One of such difficulties is the inability to confine the dosage form in the desired area of the gastrointestinal tract. Drug absorption from the gastrointestinal tract is a complex procedure and is subject to many variables. It is widely acknowledged that the extent of gastrointestinal tract drug absorption is related to contact time with the small intestinal mucosa. Thus, small intestinal transit time is an important parameter for drugs that are incompletely absorbed. Basic human physiology with the details of gastro intestinal retention, motility patterns, and physiological and formulation variables affecting the gastric emptying are summarized. ${ }^{1-2}$

\section{GASTROINTESTINAL RETENTION}

Gastro retentive can be remain in gastric region for several hours and hence significantly prolong the gastric residence time of drugs. Prolonged gastric retention improves bioavailability, reduces drug wastage and improves solubility of drugs that are less soluble in a high $\mathrm{pH}$ environment. ${ }^{3}$

It has application also for local drug delivery to the stomach and proximal small intestine. Gastro retention helps to provide better availability of new products with new therapeutic possibilities and substantial benefits to patients. ${ }^{4}$

To successfully modulate the gastro intestinal transit time of a drug delivery system through floating drug delivery system for maximal gastrointestinal absorption of drugs and site specific delivery, one needs to have a good fundamental understanding of the anatomic and physiological characteristics of the human GIT. ${ }^{5}$

\section{GASTROINTESTINAL TRACT PHYSIOLOGY}

The main function of the stomach is to process and transport food. It serves as a short term storage reservoir, allowing a rather large meal to be consumed quickly. Substantial enzymatic digestion is initiated in stomach, particularly of proteins. Vigorous contraction of gastric smooth muscle mixes and grinds food stuffs with gastric secretions, resulting in liquefaction of food. As food is liquefied in the stomach, it is slowly released into small intestine for further processing. ${ }^{6}$

Basically stomach is divided into 3 regions: fundus, body, and antrum (pylorus). The proximal part made of fundus and body acts as a reservoir for undigested material, the antrum is the main site for mixing motions and act as a pump for gastric emptying by propelling actions. ${ }^{7}$ Gastric emptying occurs during fasting as well as fed states. The pattern of motility is however distinct in the 2 states. During the fasting state an inter-digestive series of electrical events take place, which cycle both through stomach and intestine every 2 to 3 hours. ${ }^{8}$ This is called the inter-digestive myloelectric cycle or migrating myloelectric cycle (MMC), which is further divided into 
following 4 phases as described by Wilson and Washington. ${ }^{9}$

Phase I (basal phase) lasts from 40 to 60 minutes with rare contractions.

Phase II (pre-burst phase) lasts for 40 to 60 minutes with intermittent action potential and contractions. As the phase progresses the intensity and frequency also increases gradually.

Phase III (burst phase) lasts for 4 to 6 minutes. It includes intense and regular contractions for short period. It is due to this wave that all the undigested material is swept out of the stomach down to the small intestine. It is also known as the housekeeper wave.

Phase IV lasts for 0 to 5 minutes and occurs between phases III and I of 2 consecutive cycles.

After the ingestion of a mixed meal, the pattern of contractions changes from fasted to that of fed state. This is also known as digestive motility pattern and comprises continuous contractions as in phase II of fasted state. These contractions result in reducing the size of food particles (to less than $1 \mathrm{~mm}$ ), which are propelled toward the pylorus in a suspension form. During the fed state onset of MMC is delayed resulting in slowdown of gastric emptying rate. Scintigraphic studies determining gastric emptying rates revealed that orally administered controlled release dosage forms are subjected to basically 2 complications, that of short gastric residence time and unpredictable gastric emptying rate. ${ }^{10}$

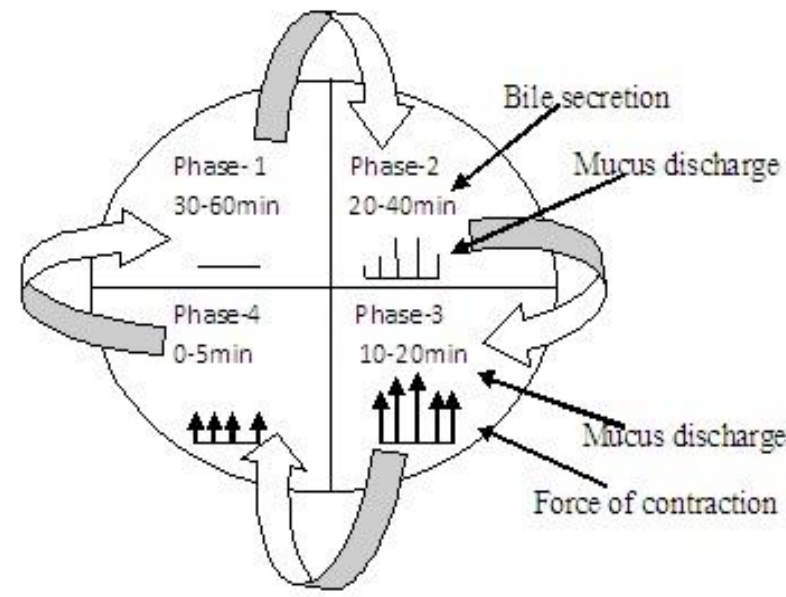

Figure 1: Motility pattem of git

\section{FACTORS AFFECTING GASTRIC RESIDENCE T IME OF FDDS}

The gastric retention time (GRT) of dosage form is controlled by several factors that affect their efficacy as a gastro retentive system.

- Density - GRT is a function of dosage form buoyancy that is dependent on the density. ${ }^{11}$

- Size - Dosage form units with a diameter of more than $9.5 \mathrm{~mm}$ are reported to have an increased GRT. ${ }^{12}$

- Shape of dosage form - Tetrahedron and ringshaped devices with a flexural modulus of 48 and 22.5 kilo pounds per square inch (KSI) are reported to have better GRT. $90 \%$ to $100 \%$ retention at 24 hours compared with other shapes.

- Single or multiple unit formulation - Multiple unit formulations show a more predictable release profile and insignificant impairing of performance due to failure of units, allow co- administration of units with different release profiles or containing incompatible substances and permit a larger margin of safety against dosage form failure compared with single unit dosage forms.

- Fed or unfed state - Under fasting conditions, the GI motility is characterized by periods of strong motor activity or the migrating myoelectric complex (MMC) that occurs every 1.5 to 2 hours. The MMC sweeps undigested material from the stomach and, if the timing of administration of the formulation coincides with that of the MMC, the GRT of the unit can be expected to be very short. However, in the fed state, MMC is delayed and GRT is considerably longer.

- $\quad$ Nature of meal - Feeding of indigestible polymers or fatty acid salts can change the motility pattern of the stomach to a fed state, thus decreasing the gastric emptying rate and prolonging drug release.

- Caloric content - GRT can be increased by four to 10 hours with a meal that is high in proteins and fats. $^{13}$

- $\quad$ Frequency of feed - The GRT can increase by over 400 minutes when successive meals are given compared with a single meal due to the low frequency of MMC.

- $\quad$ Gender - Mean ambulatory GRT in males (3.4 \pm 0.6 hours) is less compared with their age and racematched female counterparts (4.6 \pm 1.2 hours), regardless of the weight, height and body surface.

- Age - Elderly people, especially those over 70, have a significantly longer GRT.

- $\quad$ Posture - GRT can vary between supine and upright ambulatory states of the patient. ${ }^{14}$

- Concomitant drug administrationAnticholinergics like Atropine and Propantheline, Opiates like Codeine and Prokinetic agents like Metoclopramide and Cisapride.

- Biological factors - Diabetes and Crohn's disease.

\section{SUITABLE DRUGS FOR GASTRORETENTION ${ }^{15}$}

Delivery of the Drugs in continuous and controlled mann er have a lower level of side effects and provide their eff ects without the need for repeated dosing with a low do sage frequency.Sustained release in the stomach is also $u$ seful for therapeutic agents that the stomach does not $r$ eadily absorb, since sustained release prolongs the contac $\mathrm{t}$ time of the agent in the stomach or in the upper $\mathrm{p}$ art of the small intestine, from where absorption occurs a nd contact time is limited. Appropriate candidates for controlled release gastroretentive dosage forms are molecules that have poor colonic absorption but are characterized by better absorption properties at the upper parts of the GIT.

- Narrow absorption window in GI tract, e.g., riboflav in and levodopa 
- Basically absorbed from stomach and upper part o f GIT, e.g., chlordiazepoxide and cinnarazine.

- Drugs that disturb normal colonic bacteria, e.g., a moxicillin trihydrate.
- Locally active in the stomach, e.g., antacids and mis oprostol.

- Drugs that degrade in the colon, e.g., ranitidine $\mathrm{HCl}$ and metronidazole.

\section{APPROACHES TO GASTRORETENTION}

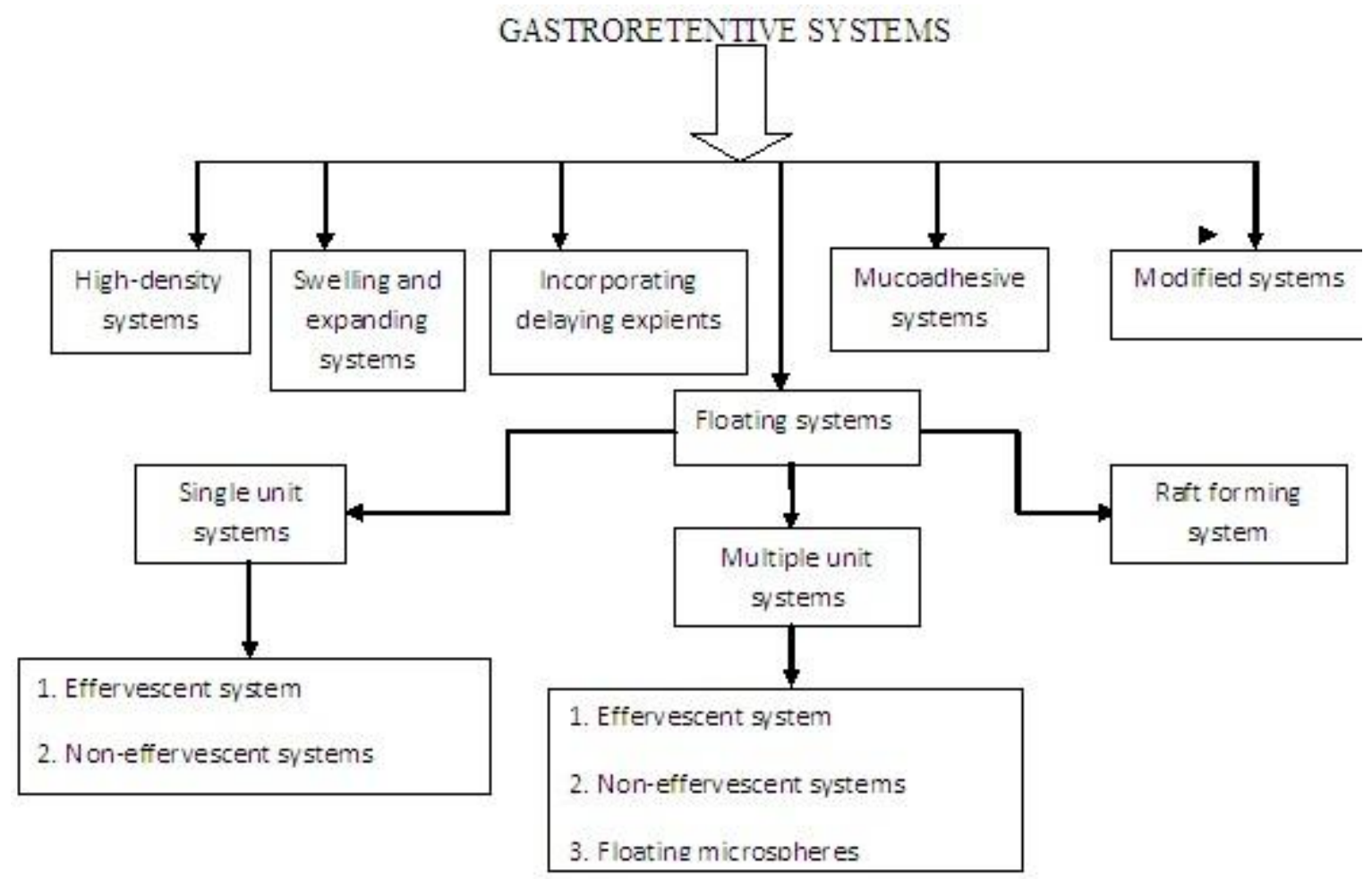

Fig 2: Schematic representation of various gastro retentive formulations

Several techniques are reported in the literature to in crease the gastric retention of drugs.

\section{1) High-density systems}

These systems, which have a density of $\sim 3 \mathrm{~g} / \mathrm{cm} 3$, are ret ained in the stomach and capableof withstanding its peristaltic movements. The only major drawback wit $\mathrm{h}$ the systems is that it is technically difficult to manuf acture them with a large amount of drug (>50\%) and achi eve required density of $2.4-2.8 \mathrm{~g} / \mathrm{cm}^{3}$. Diluents such a barium sulphate (density= 4.9),zinc oxide, titanium oxide, and iron powder must be used to manufacture such hi ghdensityformulation. ${ }^{16}$

\section{2) Swelling and expanding systems}

These systems are also called as "Plug type system" , since they exhibit tendency to remain logged in the pyloric sphincters. These polymeric matrices remain in $\mathrm{t}$ he gastric cavity for several hours even in fed state.

By selection of polymer with the proper molecular weight and swelling properties controlled and sustained drug release can be achieved. Upon coming in contact $\mathrm{w}$ ith gastric fluid, the polymer imbibes water and swells. $T$ he extensive swelling of these polymers is a result of $\mathrm{t}$ he presence of physical-chemical cross links in the hydro philic polymer network.

These cross link prevents the dissolution of polymer and thus maintain the physical integrity of the dosage form. A high degree of cross linking retards the swelling abilit $\mathrm{y}$ of the system and maintains its physical integrity for prolongedperiod. On the other hand, a low degree of cross linking results in extensive swelling followed by th e rapid dissolution of polymer.

\section{3) Incorporating delaying excipients}

Another delayed gastric emptying approach of interes $t$ include feeding of digestible polymers or fatty acid sa lts that charges the motility pattern, of the stomach to a $\mathrm{f}$ ed stage thereby decreasing the gastric emptying rate an $\mathrm{d}$ permitting considerable prolongation of the drug rel ease. Prolongation of GRT of drug delivery system consists of incorporating delaying excipients like trie tanolamine myristate in a delivery system. ${ }^{17}$

\section{4) Modified systems}

Systems with non disintegrating geometric shape mo ulded from silastic elastomers or extruded from polye thylene blends, which extend the GRT depending on si ze, shape and flexural modules ofdrug delivery device. ${ }^{1}$

\section{5) Mucoadhesive \& bioadhesive systems}

Bioadhesive drug delivery systems are used to localize a delivery device within the lumen to enhance the drug abs orption in a site-specific manner. This approach involves the use of bioadhesive polymers, which can adhere $t$ o the epithelial surface in the stomach. Some of the $\mathrm{m}$ ost promising excipients that have been used commo nly in these systems include polycarbophil, carbopol, le ctins, chitosan, CMC and gliadin, etc. 


\section{6) Floating systems}

Floating drug delivery systems (FDDS) have a bulk dens ity less than gastric fluids and so remain buoyant in the stomach without affecting the gastric emptying rate for a prolongedperiod of time. While the system is floa ting on the gastric contents, the drug is releasedslowly a $t$ the desired rate from the system. After releaseof drug, $t$ he residual system is emptied from the stomach. Floatati on of a drug delivery system in the stomach can be achieved by incorporating floating chamber filled with vacuum, air, or inert gas. ${ }^{19}$

\section{CLASSIFICATION OF FLOATING DRUG DELIVERY SYSTEM}

A. Single Unit Floating Dosage Systems

a) Effervescent Systems (Gas-generating Systems)

b) Non-effervescent Systems

B. Multiple Unit Floating Dosage Systems

a) Non-effervescent Systems

b) Effervescent Systems (Gas-generating Systems)

c) Hollow Microspheres

C. Raft Forming Systems

\section{A. Single Unit Floating Dosage Systems}

\section{a) Effervescent Systems (Gas-generating Systems)}

These buoyant systems utilized matrices prepared with swellable polymers like HPMC, polysaccharides like chitosan, effervescent components like sodium bicarbonate, citric acid and tartaric acid or chambers containing a liquid that gasifies at body temperature. The optimal stoichiometric ratio of citric acid and sodium bicarbonate for gas generation is reported to be $0.76: 1$. The common approach for preparing these systems involves resin beads loaded with bicarbonate and coated with ethylcellulose. The coating, which is insoluble but permeable, allows permeation of water. Thus, carbon dioxide is released, causing the beads to float in the stomach. Excipients used most commonly in these systems include HPMC, polyacrylate polymers, polyvinyl acetate, Carbopol ${ }^{\circledR}$, agar, sodium alginate, calcium chloride, polyethylene oxide and polycarbonates. ${ }^{20}$

\section{b) Non-Effervescent Systems}

This type of system, after swallowing, swells unrestrained via imbibitions of gastric fluid to an extent that it prevents their exit from the stomach. These systems may be referred to as the 'plug-type systems' since they have a tendency to remain lodged near the pyloric sphincter. One of the formulation methods of such dosage forms involves the mixing of drug with a gel, which swells in contact with gastric fluid after oral administration and maintains a relative integrity of shape and a bulk density of less than one within the outer gelatinous barrier. The air trapped by the swollen polymer confers buoyancy to these dosage forms. Examples of this type of FDDS include colloidal gel barrier, micro porous compartment system, alginate beads, and hollow microspheres. Another type is a Fluidfilled floating chamber which includes incorporation of a gas-filled floatation chamber into a micro porous component that houses a drug reservoir. Apertures or openings are present along the top and bottom walls through which the gastrointestinal tract fluid enters to dissolve the drug. The other two walls in contact with the (c) 2011-14, JDDT. All Rights Reserved fluid are sealed so that the undissolved drug remains therein. The fluid present could be air, under partial vacuum or any other suitable gas, liquid, or solid having an appropriate specific gravity and an inert behaviour. The device is of swallowable size, remains afloat within the stomach for a prolonged time and after the complete release the shell disintegrates, passes off to the intestine, and is eliminated. A newer self-correcting floatable asymmetric configuration drug delivery system has a 3layermatrix to control the drug release. This 3-layer principle has been improved by development of an asymmetric configuration drug delivery system in order to modulate the release extent and achieve zero-order release kinetics by initially maintaining a constant area at the diffusing front with subsequent dissolution/erosion toward the completion of the release process. The system was designed in such a manner that it floated to prolong gastric residence time in vivo, resulting in longer total transit time within the gastrointestinal tract environment with maximum absorptive capacity and consequently greater bioavailability. This particular characteristic would be applicable to drugs that have $\mathrm{pH}$-dependent solubility, a narrow window of absorption, and are absorbed by active transport from either the proximal or distal portion of the small intestine., ${ }^{7,20}$

\section{B. Multiple Unit Floating Systems}

In spite of extensive research and development in the area of hydro dynamically balanced systems and other floating tablets, these systems suffer from an important drawback of high variability of gastrointestinal transit time, when orally administered, because of their all-ornothing gastric emptying nature. In order to overcome the above problem, multiple unit floating systems were developed, which reduce the inter-subject variability in absorption and lower the probability of dose- dumping. Reports have been found on the development of both non-effervescent and effervescent multiple unit systems . Much research has been focused and the scientists are still exploring the field of hollow microspheres, capable of floating on the gastric fluid and having improved gastric retention properties. ${ }^{21}$

\section{a) Non-effervescent Systems}

No much report was found in the literature on noneffervescent multiple unit systems, as compared to the effervescent systems. However, few workers have reported the possibility of developing such system containing indomethacin, using chitosan as the polymeric excipient. A multiple unit HBS containing indomethacin as a model drug prepared by extrusion process is reported. A mixture of drug, chitosan and acetic acid is extruded through a needle, and the extrudate is cut and dried. Chitosan hydrates and floats in the acidic media, and the required drug release could be obtained by modifying the drug-polymer ratio. ${ }^{22}$

\section{b) Effervescent Systems (Gas-generating Systems)}

There are reports of sustained release floating granules containing tetracycline hydrochloride. The granules are a mixture of drug granulates of two stages $\mathrm{A}$ and $\mathrm{B}$, of which A contains 60 parts of HPMC, 40 parts of polyacrylic acid and 20 parts of drug and B contains 70 parts of sodium bicarbonate and 30 parts of tartaric acid. 60 parts by weight of granules of stage $A$ and 30 parts by weight of granules of stage $B$ are mixed along with a lubricant and filled into capsule. In dissolution media, ISSN: 2250-1177
CODEN (USA): JDDTAO 
the capsule shell dissolves and liberates the granules, which showed a floating time of more than $8 \mathrm{~h}$ and sustained drug release of $80 \%$ in about6.5 h. Floating minicapsules of pepstatin having a diameter of 0.1-0.2 $\mathrm{mm}$ has been reported by Umezawa. These minicapsules contain a central core and a coating. The central core consists of a granule composed of sodium bicarbonate, lactose and a binder, which is coated with HPMC. Pepstatin is coated on the top of the HPMC layer. The system floats because of the $\mathrm{CO}_{2}$ release in gastric fluid and the pepstatin resides in the stomach for prolonged period. Alginates have received much attention in the development of multiple unit systems. Alginates are nontoxic, biodegradable linear copolymers composed of Lglucuronic and L-mannuronic acid residues. A multiple unit system was prepared comprises of calcium alginate core and calcium alginate/PVA membrane, both separated by an air compartment. In presence of water, the PVA leaches out and increases the membrane permeability, maintaining the integrity of the air compartment. Increase in molecular weight and concentration of PVA, resulted in enhancement of the floating properties of the system.

Freeze-drying technique is also reported for the preparation of floating calcium alginate beads. Sodium alginate solution is added drop wise into the aqueous solution of calcium chloride, causing the instant gelation of the droplet surface, due to the formation of calcium alginate. The obtained beads are freeze-dried resulting in a porous structure, which aid in floating. The authors studied the behaviour of radio labeled floating beads and compared with non- floating beads in human volunteers using gamma scintigraphy. Prolonged gastric residence time of more than $5.5 \mathrm{~h}$ was observed for floating beads. The non-floating beads had a shorter residence time with a mean onset emptying time of $1 \mathrm{~h}$.

A new multiple type of floating dosage system had developed having a pill in the core, composed of effervescent layers and swellable membrane layers coated on sustained release pills . The inner layer of effervescent agents containing sodium bicarbonate and tartaric acid was divided into 2 sublayers to avoid direct contact between the 2 agents. These sublayers were surrounded by a swellable polymer membrane containing polyvinyl acetate and purified shellac. When this system was immersed in the buffer at $37^{\circ} \mathrm{C}$, it settled down and the solution permeated into the effervescent layer through the outer swellable membrane. $\mathrm{CO}_{2}$ was generated by the neutralization reaction between the 2 effervescent agents, producing swollen pills (like balloons) with a density less than $1.0 \mathrm{~g} / \mathrm{ml}^{23}$

\section{c) Hollow Microspheres}

Hollow microspheres are considered as one of the most promising buoyant systems, as they possess the unique advantages of multiple unit systems as well as better floating properties, because of central hollow space inside the microsphere. The general techniques involved in their preparation include simple solvent evaporation and solvent diffusion and evaporation. The drug release and better floating properties mainly depend on the type of polymer, plasticizer and the solvents employed for the preparation. Polymers such as polycarbonate, Eudragit ${ }^{\circledR}$ Sand cellulose acetate were used in the preparation of hollow microspheres, and the drug release can be (c) 2011-14, JDDT. All Rights Reserved modulated by optimizing the polymer quantity and the polymer-plasticizer ratio. Sustained release floating microspheres using polycarbonate were developed, employing solvent evaporation technique. Aspirin, griseofulvin and p-nitroaniline were used as model drugs. Dispersed phase containing polycarbonate solution in dichloromethane, and micronized drug, was added to the dispersion medium containing sodium chloride, polyvinyl alcohol and methanol. The dispersion was stirred for 3-4h to assure the complete solvent evaporation, and the microspheres obtained were filtered, washed with coldwater and dried. The spherical and hollow nature of the microspheres was confirmed by Scanning electron microscopic studies. The microspheres showed a drug payload of more than $50 \%$, and the amount of drug incorporated is found to influence the particle size distribution and drug release. The larger proportion of bigger particles was seen at high drug loading, which can be attributed to the increased viscosity of the dispersed phase. ${ }^{23}$

\section{Raft Forming Systems}

Raft forming systems have received much attention for the delivery of antacids and drug delivery for gastrointestinal infections and disorders. The basic mechanism involved in the raft formation includes the formation of viscous cohesive gel in contact with gastric fluids, wherein each portion of the liquid swells forming a continuous layer called a raft. The raft floats because of the buoyancy created by the formation of $\mathrm{CO}_{2}$ and act as a barrier to prevent the reflux of gastric Contents like $\mathrm{HCl}$ and enzymes into the oesophagus. Usually, the system contains a gel forming agent and alkaline bicarbonates or carbonates responsible for the formation of to make the system less dense and float on the gastric fluids. $^{24}$

\section{ADVANTAGES OF FDDS ${ }^{25,26}$}

- The gastro retentive systems are advantageous for drugs absorbed through the stomach, e.g. ferrous salts, antacids.

- Acidic substances like aspirin cause irritation on the stomach wall when come in contact with it. Hence, hydro dynamically balanced systems (HBS) formulation may be useful for the administration of aspirin and other similar drugs.

- Administration of prolongs release floating dosage forms, tablet or capsules, will result in dissolution of the drug in the gastric fluid. They dissolve in the gastric fluid would be available for absorption in the small intestine after emptying of the stomach contents. It is therefore expected that a drug will be fully absorbed from floating dosage forms if it remains in the solution form even at the alkaline $\mathrm{pH}$ of the intestine.

- The gastro retentive systems are advantageous for drugs meant for local action in the stomach. e.g. antacids.

- When there is a vigorous intestinal movement and a short transit time as might occur in certain type of diarrhoea, poor absorption is expected. Under such circumstances it may be advantageous to keep the 
drug in floating condition in stomach to get a relatively better response.

- FDDS improves patient compliance by decreasing dosing frequency.

- Bioavailability enhances despite first pass effect because fluctuations in plasma drug concentration are avoided; a desirable plasma drug concentration is maintained by continuous drug release.

- Better therapeutic effect of short half-life drugs can be achieved.

- Gastric retention time is increased because of buoyancy.

- Enhanced absorption of drugs which solubilise only in stomach.

- Superior to single unit floating dosage forms as such microspheres releases drug uniformly and there is no risk of dose dumping.

- Avoidance of gastric irritation, because of sustained release effect, floatability and uniform release of drug through multi particulate system.

\section{LIMITATIONS OF FDDS ${ }^{27}$}

- Floating system is not feasible for those drugs that have solubility or stability problem in G.I. tract.

- These systems require a high level of fluid in the stomach for drug delivery to float and work efficiently-coat, water.

- The drugs that are significantly absorbed through out gastrointestinal tract, which undergo significant first pass metabolism, are only desirable candidate.

- Some drugs present in the floating system causes irritation to gastric mucosa.

\section{APPLICATIONS OF FDDS ${ }^{28}$}

Floating drug delivery offers several applications for drugs having poor bioavailability because of the narrow absorption window in the upper part of the gastrointestinal tract. It retains the dosage form at the site of absorption and thus enhances the bioavailability. These are summarized as follows.
- Sustained Drug Delivery: HBS systems can remain in the stomach for long periods and hence can release the drug over a prolonged period of time. The problem of short gastric residence time encountered with an oral CR formulation hence can be overcome with these systems. These systems have a bulk density of $<1$ as a result of which they can float on the gastric contents. These systems are relatively large in size and passing from the pyloric opening is prohibited.

Eg. Sustained release floating capsules of nicardipine hydrochloride were developed and were evaluated in vivo. The formulation compared with commercially available MICARD capsules using rabbits. Plasma concentration time curves showed a longer duration for administration (16 hours) in the sustained release floating capsules as compared with conventional MICARD capsules (8 hours).

- $\quad$ Site-Specific Drug Delivery: These systems are particularly advantageous for drugs that are specifically absorbed from stomach or the proximal part of the small intestine, eg, riboflavin and furosemide.

Eg. Furosemide is primarily absorbed from the stomach followed by the duodenum. It has been reported that a monolithic floating dosage form with prolonged gastric residence time was developed and the bioavailability was increased. AUC obtained with the floating tablets was approximately 1.8 times those of conventional furosemide tablets.

- Absorption Enhancement: Drugs that have poor bioavailability because of site- specific absorption from the upper part of the gastrointestinal tract are potential candidates to be formulated as floating drug delivery systems, thereby maximizing their absorption. Eg. A significantly increase in the bioavailability of floating dosage forms(42.9\%) could be achieved as compared with commercially available LASIX tablets $(33.4 \%)$ and enteric coated LASIX-long product $(29.5 \%)$.

\section{Table 1: List of Drugs Formulated as Single and Multiple Unit Forms of Floating Drug Delivery System $^{29}$}

\begin{tabular}{|l|l|}
\hline Tablets & $\begin{array}{l}\text { Cholrpheniramine maleate, Theophylline, Furosemide, Ciprofloxacin, Captopril, Acetylsalicylic acid, } \\
\text { Nimodipine, Amoxycillin trihydrate, Verapamil HCI, Isosorbide di nitrate, Sotalol, Isosorbide } \\
\text { mononitrate, Aceraminophen, Ampicillin, Cinnarazine, Dilitiazem, Florouracil, Piretanide, } \\
\text { Prednisolone, Riboflavin- 5'Phosphate. }\end{array}$ \\
\hline Capsules & $\begin{array}{l}\text { Nicardipine, L-Dopa and benserazide, chlordizepoxide HCI, Furosemide, Misoprostal, Diazepam, } \\
\text { Propranlol, Urodeoxycholic acid. }\end{array}$ \\
\hline Microspheres & Verapamil, Aspirin, Griseofulvin, and p-nitroanilline, Ketoprofen, Tranilast, Iboprufen, Terfenadine. \\
\hline Granules & Indomethacin, Diclofenac sodium, Prednisolone. \\
\hline Films & Drug delivery device. Cinnarizine \\
\hline
\end{tabular}

\section{FORMULATUION ASPECTS OF FDDS}

The design of novel controlled release dosage forms should take into account three important criteria, viz., drug, delivery, and destination. Preformulation studies help in studying the physiochemical properties of drugs.
These properties include $\mathrm{pKa}, \mathrm{pH}$, solubility, and incompatibility. The solubility of a compound affects the choice of a controlled drug delivery system. If the compound has very low solubility (i.e. less than $0.01 \mathrm{mg} / \mathrm{ml}$ ), it is inherently sustained. A drug has to 
cross a variety of biological membrances in order to produce a therapeutic effect when it is administered to the gastrointestinal tract. Thus a partition coefficient of a drug is important in determining penetration of these membrane barriers by the drug. Compounds with very low partition coefficients will not easily penetrate these membranes, resulting in poor bioavailability. Acid-base hydrolysis and enzymatic degradation attack orally administered drugs. Compounds such as propantheline are unstable in small intestine. This results in decrease bioavailability when administered in controlled release delivery form.

In case of oral drug delivery systems, the first destination is the gastrointestinal tract. From here the drug is absorbed and is taken to the site of action. Thus physiology of the gastrointestinal tract has a direct effect on the design of controlled release delivery systems. In addition, effects of disease conditions and coadministered drugs also affect the design. ${ }^{30}$

- Absorption window: site of absorption also favours the development of this formulation.

- Shorter biological half-life: Ranitidine hydrochloride having shorter biological half life's favours for the formulations.

- Solubility: Drug having better solubility in acidic environment and also having specific site of absorption in the upper part of the small intestine. Drug having stability at gastric $\mathrm{pH}$.

- Dose: drugs that are used locally in stomach like Ranitidine hydrochloride, famotidine (H2- receptor antagonist). It is widely used/prescribed in duodenal ulcers, gasric ulcers, zollinger ellisons syndrome, gastro oesophageal reflex disease and erosive esophagitis.

- Others: due to certain more reasons like: conventional dosages forms having poor patient compliance, increase the chance of missing dose of a drug due to shorter half life of drugs for which frequent administration is necessary. In conventional dosages forms it is very difficult to maintain plasma concentration time profile in steady state manner due to missing of dose. The unavoidable fluctuations in the drug concentration may lead to under medication or overmedication.

\section{PHARMACOKINETIC AND PHARMACO- DYNAMIC ASPECTS OF FDDS}

The aim of this section is to delineate these aspects in order to suggest rational selection of drugs for which FDDS would be a beneficial strategy. ${ }^{31-34}$

\section{PHARMACOKINETIC ASPECTS}

- Absorption window: Validation that the drug is within the category of narrow absorption window agents currently various experimental techniques are available that permit us to verify the absorption properties of the tested molecule, to determine the mechanism of intestinal absorption and to elucidate the permeability at different regions of the GI tract. In the case of absorption by active transporters that are capacity limited, the efficacy of the transport activity may increase following sustained presentation of the drug to the transporting enzymes in comparison to non-control release mode of administration.

- Enhanced bioavailability: Once it has been ascertained that the compound in question is defined as narrow absorption window, the possibility of improving bioavailability by continuous administration of the compound to the specific site should be tested. For example, we have found that certain bisphosphonates, including alendronate, are absorbed directly from the stomach. However, the magnitude of this pathway remains modest even in the case where the prolonged gastric retention of the bisphosphonate in rats is produced by experimental or surgical means. On the other hand, the bioavailability of control release (CR) floating systems of Riboflavin and Levodopa are significantly enhanced in comparison to administration of simple $\mathrm{CR}$ polymeric formulations. It may be concluded that several different processes, related to absorption and transit of the drug in the gastrointestinal tract, act concomitantly and influence the magnitude of drug absorption. Therefore, in vivo studies are necessary to determine the release profile of the drug from the dosage form that will provide enhanced bioavailability

- Enhanced first pass biotransformation: In a similar fashion to increased efficacy of active transporters exhibiting capacity limited activity, the pre-systemic metabolism of the tested compound may be considerably increased when the drug is presented to the metabolic enzymes (cytochrome P450, in particular CYP3A4) in a sustained manner, rather than by a bolus input.

- Improved bioavailability due to reduced Pglycoprotein (P-gp) activity in the duodenum: In apparent contrast to the higher density of CYP3A4 at the upper part of the intestine, P-gp mRNA levels increase longitudinally along the intestine such that the highest levels are located in the colon. Therefore, for drugs that are P-gp substrate and do not undergo oxidative metabolism, such as Digoxin, floating systems may elevate absorption compared to the immediate and CR dosage forms.

- Reduced frequency of dosing: For drugs with relatively short biological half-life, sustained and slow input from control release floating system may result in a flip-flop pharmacokinetics and enable reduced dosing frequency. This feature is associated with improved patient compliance, and thereby improves therapy.

- $\quad$ Targeted therapy for local ailments in the upper GIT: The prolonged and sustained administration of the drug from the floating systems to the stomach may be advantageous for local therapy in the stomach and the small intestine.

\section{PHARMACODYNAMIC ASPECTS}

- Reduced fluctuations of drug concentration: Continuous input of the drug following floating system administration produces blood drug concentrations within a narrower range compared to the immediate release dosage forms. Thus, 
fluctuations in drug effects are minimized and concentration dependent adverse effects that are associated with peak concentrations can be prevented. This feature is of special importance for drugs with a narrow therapeutic index

- Improved selectivity in receptor activation: Minimization of fluctuations in drug concentration also makes it possible to obtain certain selectivity in the elicited pharmacological effect of drugs that activate different types of receptors at different concentrations.

- Reduced counter-activity of the body: In many cases, the pharmacological response, which intervenes with the natural physiologic processes, provokes a rebound activity of the body that minimizes drug activity. Slow input of the drug into the body was shown to minimize the counter activity leading to higher drug efficiency.

- Minimized adverse activity at the colon: Retention of the drug in the GRDF at the stomach minimizes the amount of drug that reaches the colon. Thus, undesirable activities of the drug in colon may be prevented. This pharmacodynamic aspect provides the rationale for floating formulation for beta-lactam antibiotics that are absorbed only from the small intestine and presence in the colon leads to development of microorganisms. ${ }^{35}$

\section{EVALUATION TECHNIQUES FOR FDDS}

In vitro evaluation of floating tablets Evaluation was performed to assess the physicochemical properties and release characteristics of the developed formulations.

\section{Pre-compression parameters}

\section{a) Angle of Repose ${ }^{36}$}

The frictional forces in a loose powder or granules can be measured by angle of repose. This is the maximum angle possible between the surface of a pile of powder or granules and the horizontal plane.

The granules were allowed to flow through the funnel fixed to a stand at definite height $(\mathrm{h})$. The angle of repose was then calculated by measuring the height and radius of the heap of granules formed.

$$
\begin{aligned}
& \tan \Theta=\mathrm{h} / \mathrm{r} \\
& \Theta=\tan ^{-1}(\mathrm{~h} / \mathrm{r})
\end{aligned}
$$

Where, $\theta=$ angle of repose

$$
\mathrm{h}=\text { height of the heap }
$$$$
\mathrm{r}=\text { radius of the heap }
$$

The relationship between Angle of repose and powder flow is as follows in table 2 .

Table 2: Relationship between angle of repose and powder flow

\begin{tabular}{|l|l|}
\hline Angle of repose & Powder flow \\
\hline$<25$ & Excellent \\
$25-30$ & Good \\
$30-40$ & Passable \\
$>40$ & Very poor \\
\hline
\end{tabular}

b) Compressibility Index

The flowability of powder can be evaluated by comparing the bulk density ( $\rho$ ) and tapped density ( $\rho \mathrm{t}$ ) of powder and the rate at which it packed down. Compressibility index was calculated by -

$$
\text { Compressibility index }(\%)=\rho^{t}-\rho^{o} / \rho^{t} \times 100
$$

Where, $\rho$ o $=$ Bulk density $\mathrm{g} / \mathrm{ml} 002 \mathrm{E}$

$$
\rho^{\mathrm{t}}=\text { Tapped density } \mathrm{g} / \mathrm{ml} \text {. }
$$

II Post-compression parameters

\section{a) Shape of Tablets}

Compressed tablets were examined under the magnifying lens for the shape of the tablet.

\section{b) Tablet Dimensions}

Thickness and diameter were measured using a calibrated Vernier calliper. Three tablets of each formulation were picked randomly and thickness was measured individually.

\section{c) Hardness ${ }^{37}$}

Hardness indicates the ability of a tablet to withstand mechanical shocks while handling. The hardness of the tablets was determined using Monsanto hardness tester. It was expressed in $\mathrm{kg} / \mathrm{cm}^{2}$. Three tablets were randomly picked and hardness of the tablets was determined.

\section{d) Friability test}

The friability of tablets was determined by using Roche Friabilator. It was expressed in percentage (\%). Ten tablets were initially weighed $\left(\mathrm{W}_{\text {initial }}\right)$ and transferred into friabilator. The friabilator was operated at $25 \mathrm{rpm}$ for 4 minutes or run up to 100 revolutions. The tablets were weighed again $\left(\mathrm{W}_{\text {final }}\right)$. The $\%$ friability was then calculated by -

$$
\% \mathrm{~F}=100\left(1-\mathrm{W}_{\text {final }} / \mathrm{W}_{\text {initial }}\right)
$$

$\%$ Friability of tablets less than $1 \%$ was considered acceptable.

\section{e) Tablet Density ${ }^{38}$}

Tablet density was an important parameter for floating tablets. The tablet would floats only when its density was less than that of gastric fluid (1.004). The density was determined using following relationship.

$$
\begin{aligned}
& \mathrm{V}=\pi \mathrm{r}^{2} \mathrm{~h} \\
& \mathrm{~d}=\mathrm{m} / \mathrm{v}
\end{aligned}
$$

Where, $\mathrm{v}=$ volume of tablet $(\mathrm{cc})$

$$
\begin{aligned}
\mathrm{r} & =\text { radius of tablet }(\mathrm{cm}) \\
\mathrm{h} & =\text { crown thickness of tablet }(\mathrm{g} / \mathrm{cc}) \\
\mathrm{m} & =\text { mass of tablet }
\end{aligned}
$$

\section{f) Weight Variation Test}

Ten tablets were selected randomly from each batch and weighed individually to check for weight variation. A little variation was allowed in the weight of a tablet by U.S. Pharmacopoeia. The following percentage deviation in weight variation was allowed show in table 3 .

Table 3: Percentage deviation in weight variation

\begin{tabular}{|l|l|}
\hline \multicolumn{1}{|c|}{$\begin{array}{c}\text { Average weight of a } \\
\text { tablet }\end{array}$} & \multicolumn{1}{c|}{ Percent deviation } \\
\hline $130 \mathrm{mg}$ or less & 10 \\
\hline$>130 \mathrm{mg}$ and $<324 \mathrm{mg}$ & 7.5 \\
\hline $324 \mathrm{mg}$ or more & 5 \\
\hline
\end{tabular}




\section{g) Buoyancy / Floating Test}

The time between introduction of dosage form and its buoyancy on the simulated gastric fluid and the time during which the dosage form remain buoyant were measured. The time taken for dosage form to emerge on surface of medium called Floating Lag Time (FLT) or Buoyancy Lag Time (BLT) and total duration of time by which dosage form remain buoyant is called Total Floating Time (TFT).

\section{h) Swelling Study}

The swelling behaviour of a dosage form was measured by studying its weight gain or water uptake. The dimensional changes could be measured in terms of the increase in tablet diameter and/or thickness over time. Water uptake was measured in terms of percent weight gain, as given by the equation.

$$
\mathrm{W}_{\mathrm{U}}=\left(\mathrm{W}_{\mathrm{t}}-\mathrm{W}_{0}\right) / \mathrm{W}_{0} \times 100
$$

Where, $\mathrm{W}_{\mathrm{t}}=$ Weight of dosage form at time $\mathrm{t}$.

$\mathrm{W}_{0}=$ Initial weight of dosage form.

\section{j) In vitro drug release studies}

The test for buoyancy and in vitro drug release studies are usually carried out in simulated gastric and intestinal fluids maintained at $37^{\circ} \mathrm{C}$. In practice, floating time is determined by using the USP dissolution apparatus containing $900 \mathrm{ml}$ of $0.1 \mathrm{HCl}$ as a testing medium maintained at $37^{\circ} \mathrm{C}$. The time required to float the $\mathrm{HBS}$ dosage form is noted as floating (or floatation) time. Dissolution tests are performed using the USP dissolution apparatus. Samples are withdrawn periodically from the dissolution medium, replenished with the same volume of fresh medium each time, and then analyzed for their drug contents after an appropriate dilution. Recent methodology as described in USP XXIII states that the dosage unit is allowed to sink to the bottom of the vessel before rotation of blade is started. A small, loose piece of non reactive material such as not more than a few turns of wire helix may be attached to the dosage units that would otherwise float. However, standard dissolution methods based on the USP or British Pharmacopoeia (BP) have been shown to be poor predictors of in vitro performance for floating dosage forms. The method, although based on the standard BP (1993)/ USP (1990) apparatus 2 methods, was modified such that paddle blades were positioned at the surface of the dissolution medium. The results obtained with this modified paddle method showed reproducible biphasic release profiles when paddle speeds were increased from 70 to $100 \mathrm{rpm}$ and the dissolution medium $\mathrm{pH}$ was varied from 6.0 to 8.0. The dissolution profile was also unaltered when the bile acid concentration in the dissolution medium was increased from 7 to $14 \mathrm{mM}$. In contrast, the standard paddle or basket method, as described in the BP (1993) was unable to provide either sufficient mixing of the dissolution medium to disperse oily rapid release material or sufficient mechanical erosion of the SR component of the formulation. In additional studies, the authors modified a standard dissolution vessel for more reliable assessment of the performance of the floating dosage forms, particularly those which rely on an erosion mechanism for drug release. The result showed a more reproducible dissolution profile while eliminating the need for the positioning of the paddle blades at the surface of the dissolution medium, thereby simplifying sampling procedures and preventing the adhesion of dosage forms to the paddle blades. Nevertheless, the method retained its ability to differentiate between acceptable and unacceptable dissolution performance. The specific gravity of floating drug delivery system (FDDS) can be determined by the displacement method using analytical grade benzene as a displacing medium. ${ }^{39}$

Table 4: Dosage Forms of FDDS with Examples of Various Drugs ${ }^{40-42}$

\begin{tabular}{|l|l|l|}
\hline Sr. No & Dosage Forms & DRUGS \\
\hline 1 & Floating tablet & $\begin{array}{l}\text { Acetaaminophen, Acetylsalicylic acid, Ampicillin, Amoxicillin } \\
\text { trihydrate, Atenolol, Captopril, Cinnerzine, Diltiazem, Fluorouracil, } \\
\text { Isosorbide dinitrate, Isosorbide mononitrate, p-aminobenzoic acid }\end{array}$ \\
\hline 2 & Floating capsule & $\begin{array}{l}\text { Furosemide, L-DOPA, Benserazide, Nicardipine, Misoprostol, } \\
\text { Propanolol, Pepstatin }\end{array}$ \\
\hline 3 & Floating microsphere & $\begin{array}{l}\text { Aspirin, Griseofulvin, p-nitro aniline, Ibuprofen, Terfinadine, } \\
\text { Tranilast }\end{array}$ \\
\hline 4 & Floating granules & Cinnerzine, p-aminobenzoic acid, prednisolon, quinidine gluconate. \\
\hline 5 & Powders & Several basic drugs- Riboflavin phosphate, Sotalol, Theophylline \\
\hline 6 & Film & Cinnerzine, p-aminobenzoic acid, prednisolon, quinidine gluconate \\
\hline 7 & Multiple unit floating dosage form & Clarithromycin, p-aminobenzoic acid \\
\hline 8 & Bilayer Tablet & Misoprostal \\
\hline 9 & Foams/ Hollow Bodies & Ibuprofen \\
\hline 10 & Floating controlled release capsule & Levodopa, Benserazide \\
\hline 11 & $\begin{array}{l}\text { Effervescent floating liquid alginate } \\
\text { preparation }\end{array}$ & Aluminium hydroxide, Magnesium carbonate \\
\hline 12 & Floating liquid alginate preparation & Aluminium-Magnesium antacid \\
\hline 13 & Colloidal gel forming FDDS & Ferrous sulphate \\
\hline
\end{tabular}


Table 5: Marketed Formulation of Floating Drug Delivery System ${ }^{43-46}$

\begin{tabular}{|l|l|l|l|l|}
\hline $\begin{array}{l}\text { Sr. } \\
\text { No }\end{array}$ & Brand Name & Drug & Dosage Form & Company, Country \\
\hline 1 & Topalkan & Al-Mg Antacid & Floating liquid Alginate Preparation & Pierre Fabre Drug, France \\
\hline 2 & $\begin{array}{l}\text { Liquid } \\
\text { Gavison }\end{array}$ & $\begin{array}{l}\text { Al(OH })_{3}, \text { Magnesium } \\
\text { carbonate }\end{array}$ & $\begin{array}{l}\text { Efferervescent Floating Liquid } \\
\text { Alginate Preparation }\end{array}$ & Glaxo Smith Kline, India \\
\hline 3 & Valrelease & Diazepam & Floating Capsule & Hoffmann- LaRoche, USA \\
\hline 4 & Madopar & Levodopa, Benserazide & Floating Controlled Release Capsule & Roche Products, USA \\
\hline 5 & Cifran OD & Ciprofloxacin & Gas- generating Floating Tablets & Ranbaxy, India \\
\hline 6 & Conviron & Ferrous sulphate & Colloidal Gel Forming Capsule & Ranbaxy, India \\
\hline 7 & Cytotec & Misoprostal & Bilayer Floating Capsule & Pharmacia, USA \\
\hline 8 & Oflin OD & Ofloxacin & Gas generating floating tablet & Ranbaxy, India \\
\hline
\end{tabular}

\section{REFERENCES}

1. Chandel A, Chauhan K et al., Floating drug delivery systems: A better approach, International Current Pharmaceutical Journal 2012, 1(5), 110-118.

2. Hirtz $J$, The gastrointestinal absorption of drugs in man: a review of current concepts and methods of investigation, $\mathrm{Br} \mathbf{J}$ Clin Pharmacol, 1985, 19, 77S-83S

3. Narangi $\mathrm{N}$, An updated review on floating drug delivery system, International Journal of Applied Pharmaceutics, 2011, 3(1), 1-7.

4. Koner P, Saudagar RB, Dharwal J, Gastro-retentive drugs a novel approach towards floating therapy, http://www.p harmainfo.net/exlusive/reviews/gastro-

retentive drugs a novel approach towards floating therapy/, 20 07.

5. Arora S, Ali A, Ahuja A, Khar RK, Baboota S, Floating drug delivery systems: A revie, AAPS Pharm Sci Tech 2005, 6(3), E372- E390.

6. Patel GM, Floating drug delivery system: An innovative appr oach to prolong gastric retention, www.pharmainfo.net, 200 7.

7. Desai S, A novel floating controlled release drug delivery

system based on a dried gel matrix network [master's t hesis], Jamaica, NY: St John's University,1984.

8. Vantrappen G.R, Peeters T.L, Janssens J, The secretory component of inter digestive migratory motor complex in man, Scand J Gastroenterol, 1979, 14, 663-667.

9. Wilson CG, Washington N, The Stomach: its role in oral drug delivery, Physiological pharmaceutics: biological barriers to drug absorption, Ellis Howard, Chechester, 1989, 47-70.

10. Desai S, Bolton S, A floating controlled release drug delivery system: in vitro- in vivo evaluation, Pharm Reserch, 1993, 10(9), 1321-1325.

11. Rocca DJG, Omidian $\mathrm{H}$, Shah $\mathrm{K}$, Progresses in gastroretentive drug delivery systems, Business Briefing, Pharmatech, 2003, 152-156.

12. Moes AJ, Gastric retention systems for oral drug delivery, Business Briefing, Pharmatech 2003, 157-159.

13. Sharma N, Agarwal MK ET AL., A comprehensive review on floating drug delivery system, International Journal of Research in Pharmaceutical and Biomedical Sciences, 2 (2), 2011, 428-441.

14. Well LJ, Gardner RC, Cargill RC, Drug delivery device which can be retained in the stomach for a controlled period of time, US Patent 1998, 30th August: 4, 767, 627.

15. Vinod KR, Santhosh Vasa, Anbuazaghan S, David Banji1, Padmasri A, Sandhya S. Approaches for Gastroretentive Drug Delivery Systems, 1(2), 2010, 589-601.

16. Chawla G, Gupta P, Koradia V, Bansal AK, Gastroretention: A Means to address regional variability in intestinal dru g absorption, Pharm Tech 2003, 27, 250-268.

17. Gupta P, Virmani K, Garg S, Hydrogels: From controlled rele ase to $\mathrm{pH}$ responsive drug delivery, Drug Discovery Today, 2002, 7(10), 569-579.

18. Kedzierewicz F, Thaivenot P, Lemut J, Etienne A, Hoffman $\mathrm{M}$, Maincent $\mathrm{P}$, Evaluation for peroral silicon dosage for $\mathrm{ms}$ in human by gamma-scintigraphy, $\mathbf{J}$ Control Release, 1999, 58, 195-205

19. Mayavanshi AV, Gajjar SS, Floating drug delivery systems t o increase gastric retention of drugs: A Review, J Phar $\mathrm{m}$ Tech, 2008, 1(14), 345-348.

20. Rubinstein A, Friend D.R, Specific delivery to the gastrointestinal tract, in: Domb A. J (Ed.), Polymeric SiteSpecific Pharmacotherapy, Wiley, Chichester, 1994, 282-283.

21. Iannuccelli V, Copp G, Sansone R, Ferolla G, Air compartment multiple-unit system for prolonged gastric residence part II in-vivo evaluation, International Journal of Pharmaceutics, 1998, 174,55-62.

22. Tardi P, Troy H, (2002) European patent no.EP1432402.

23. Gholap SB, Banarjee SK, Gaikwad DD, Jadhav SL, Thorat R M, Hollow microspheres: A Review, International Journal of pharma science research 2010, 1 (1), 74-79.

24. Paterson RS, Omahony B, Eccleston GM, Stevens HNE, Fost er J, Murray JG, An assessment of floating raft formation in a man using magnetic resonance imaging, Journal of Pharm Pharmacol, 2008, 8, S2 (suppl).

25. Babu VBM, Khar RK, In vitro and In vivo studies of sustained release floating dosage forms containing salbutamol sulphate, Pharmazie, 1990, 45, 268-270.

26. Hetal N K, A Thesis on floating drug delivery system, The North Gujarat University, Patan, 2000-2001, 11-12.

27. Chungi VS, Dittert LW, Smith RB, Gastrointestinal sites of furosemide absorption in rats, International Journal of Pharmaceutics, 1979, 4, 27-38.

28. Moursy NM, Afifi NH, Ghorab DM, El SY, Formulation and evaluation of sustained release capsules of nicardipine hydrochloride, Pharmazie, 2003, 58(1), 38-43.

29. Mayavanshi AV, Gajjar SS, Floating drug delivery systems to increase gastric retention of drugs: A Review, Research J. Pharm. and Tech, 2008, 1(4), 345-348.

30. Davis SS, Stockwell AF, Taylor MJ, Hardy JG, Whalley DR, Wilson CG, Bechrgaard H, Cristen FN, The effect of density on the gastric emptying of single and multiple-unit dosage forms, Pharm. Res, 1986, 3, 208.

31. Ezra A, Hoffman A, A peptide prodrug approach for improving bisphosphonate oral absorption, J Med Chem., 2000, 43: 3641-3652.

32. Klausner EA, Lavy E, Stepensky D, Friedman M, Hoffman A, Novel gastroretentive dosage forms: evaluation of gastroretentivity and its effect on riboflavin absorption in dogs, Pharm Res. 2002, 19, 1516-1523.

33. Urquhart J, Theeuwes F, Drug delivery system comprising a reservoir containing a plurality of tiny pills, US Patent 4, 1984 February 28; 434 and 153.

34. Shaha $\mathrm{SH}$ et al, Gastro-retentive floating drug delivery system, Asian Journal of Pharmaceutical Sciences, 2009, 4 (1), 65-80.

35. Rosa et al, Dosing and testing in-vitro of a bio-adhesive and floating drug delivery system for oral application, Int $\mathbf{J}$ Pharm, 1994, 105, 65-70.

36. Waldwell LJ, Gardner CR, Cargil RC, US Patent 4,735,804, 1988. 
37. Timmermans J, Moes AJ. Factors controlling the buoyancy and gastric retention capabilities of floating matrix capsules: New data for reconsidering the controversy, J. Pharm. Sci, 1994, 83, 18- 24.

38. Clarke GM, Newton JM, Short MD, Comparative gastrointestinal transit of pellet systems of varying density, Int. J. Pharm, 1995, 114, 1-11.

39. Mojaverian P, Vlasses PH, Kellner PE, Rocci Jr. ML, Effects of gender, posture and age on gastric residence time of an indigestible solid: Pharmaceutical Considerations. Pharma. Res, 1980, 10, 639-44.

40. Nayak KA, Maji R, Das B, Gastroretentive drug delivery systems: a review, Asian Journal of Pharmaceutical and Clinical Research, 2010, 3(1): 1-10.
41. Gronia R, Heun G, Oral dosage forms with controlled gastrointestinal transit, Drug Dev Ind Pharm, 1984, 10, 527 39.

42. Chowdhury RS, Floating drug delivery system- a new era in novel drug delivery system, IJPRBS, 2012, 1(5), 91-107.

43. Klausner EA, Lavy E, Friedman M, Hoffman A, Expandable gastroretentive dosage form, J. Control. Rel, 2003, 90, 14362.

44. Bhavana V, Khopade AJ, Jain WD, Jain NK, Targeted oral drug delivery, Indian Drugs 1996, 33, 365-73.

45. Spechler SJ, Peptic Ulcers, Gastrointestinal and Liver Disease, 7th ed. Philadelphia, PA, WB Saunders Company, 2002,747-772.

46. Atyabi F, Sharma HL, and Mohammad HAH, Fell JT, In-vivo evaluation of a novel gastroretentive formulation based on ion exchange resins, J. Control. Rel, 1996, 42, 105-13. 